\title{
Carbon neutral policy in action: The case of Bhutan
}

Climate policy across the world is proceeding at a highly variable pace, with some places very committed to decarbonizing their economies and others just beginning. Emerging nations are generally just starting along this journey. However, among the few nation states that have pledged to achieve carbon neutrality, is Bhutan, a least developed country. Carbon neutrality is an ambitious climate policy that is increasingly being recognized as necessary in order to stabilise global temperature rise at $1.5^{\circ} \mathrm{C}$. However, Bhutan is likely to face significant challenges in maintaining this status as the country balances its desire to grow in economic opportunities (GDP) and in human happiness (GNH). Little research has been conducted inside the policy processes to better understand how Bhutan will maintain carbon neutrality. Through open-ended, semi-structured interviews with key stakeholders, this study provides an inside view on the current situation and future challenges that Bhutan may face, along with the complexities associated with implementing and maintaining an ambitious carbon neutral policy. The paper highlights Bhutan's story and how it could be useful for policy learning and knowledge sharing, especially in the context of emerging nations' climate governance.

\section{Key policy insights}

- The pro-environmental Constitution of Bhutan and its Gross National Happiness (GNH) strategy provide a unique institutional set up that enables ambitious climate policy innovation.

- Bhutan's forests and hydropower provide resource advantages that support a carbon neutral pledge.

- Bhutan's carbon neutral commitment could be tested and challenged by rural-urban migration.

- Complacency towards future challenges in upholding carbon neutrality is apparent and could prevent the aggressive policy intervention that may be required.

- Varying viewpoints are emerging that could hinder the formulation of appropriate policy measures.

Keywords: Bhutan; carbon neutral; emission reduction; semi-structured interviews; developing country; climate policy; challenges

\section{Introduction}

The international climate change negotiations have prompted countries to begin the process of decarbonizing their economies, but they are yet to result in any significant reduction in global carbon emissions. Even the 2015 Paris Agreement, which has attracted over 175 national pledges to address climate change through Nationally Determined Contributions (NDCs), has been criticised as not being enough to achieve the emissions reduction required to hold global temperature rise to "well below" $2^{\circ} \mathrm{C}$, let alone the ambitious $1.5^{\circ} \mathrm{C}$ target (Bushell, Buisson, Workman, \& Colley, 2017; Höhne et al., 2017). While it is broadly accepted that countries need to transition their economies to a low carbon path in order to meet the challenge of climate change (Mulugetta \& Urban, 2010; Nishioka, 2016; Skea \& Nishioka, 2008), some argue the transition needs to go beyond this. Rogelj et al. (2015) suggest that global carbon neutrality is needed by mid-century in order to stabilise temperature rise below $1.5^{\circ} \mathrm{C}$. The Intergovernmental Panel on Climate Change (IPCC) Special Report on Global Warming of $1.5^{\circ} \mathrm{C}$ specifically focuses on how to achieve the $1.5^{\circ} \mathrm{C}$ target (IPCC, 2018). Rauland and Newman (2015) also note that pursuing economy wide carbon neutrality will be vital to achieve an $80 \%$ reduction in fossil fuel consumption by 2050 , in line with the (IPCC, 2014) recommendations for temperature stabilisation.

However, reducing emissions sufficiently is clearly a challenging task that requires both reduction in energy services demand and switching to renewable energy sources, as well as managing land in a way that enables carbon sinks to grow faster than carbon release. Haszeldine, Flude, Johnson, and Scott (2018) go further, to suggest deployment of negative 
emission technologies and carbon capture and storage. Geels, Sovacool, Schwanen, and Sorrell (2017b) have shown how the underlying factors contributing to the challenge of deep decarbonisation are complex and interconnected within socio-economic systems. Nevertheless, despite the challenges, numerous countries from around the world have made ambitious commitments at the national level to dramatically reduce their carbon emissions. Examples of these commitments are the ambitious pledges originally made by nine countries to achieve carbon neutrality (Flagg, 2015). Bhutan, a least developed country, was among these original nine nations (NEC, 2011). Most of the pledges were made during the $15^{\text {th }}$ Conference of Parties (COP15) in Copenhagen in 2009 (UNFCCC, 2009). While a global agreement was not achieved at this particular COP, these commitments demonstrated the willingness for ambitious action at the national level. Encouragingly, by COP23 in Bonn in 2017, the number of nations that pledged to achieve carbon neutrality expanded to 15 (Carbon Neutrality Coalition, 2017) and, at the time of writing, four more nations had joined the coalition ${ }^{1}$.

Fankhauser (2013) notes the importance for policy makers to cooperate and learn from one another in order to achieve such a deep transformation. Nishioka (2016) argues that in-depth case studies of nations who are able to demonstrate significant reductions have great potential to influence and assist other countries in their transition. Flagg (2018) also highlights the importance and possible role single nation case studies have in helping to better understand contemporary climate change discourse and policy. Given that the nations that have pledged for carbon neutrality are diverse in terms of development stage and country size, these could provide useful lessons for a range of other countries.

Bhutan is a small country but is typical of many emerging countries that want to balance and integrate the multiple development agendas of economic opportunity (measured by GDP), human happiness (measured by Gross National Happiness - GNH) and climate policy (measured by greenhouse gases (GHG)). Bhutan was one of the first countries to declare its intention to become, and remain, carbon neutral in perpetuity. This, then, provides an ideal case study for pursuing how an emerging nation that wants to pursue economic growth and maintain its GNH is likely to manage its carbon neutral status. A number of modelling studies have been conducted on how Bhutan can manage this integrated approach to economic development (Yangka \& Newman, 2018) but no research has yet examined the policy process from the inside, that is, from the perspective of those who are pulling the policy levers.

Through interviews with key stakeholders in Bhutan, this paper examines the current and future challenges that Bhutan may face in upholding its ambitious climate policy, how prepared the stakeholders are to address these challenges, and what the opportunities and solutions may be to ensure Bhutan maintains its carbon neutral status into the future. This paper contributes to the climate change policy discourse by highlighting the complexities of pursuing carbon neutral policy, especially in emerging countries seeking to pursue growth objectives. The paper thus gives examples of areas that might need to be addressed by other countries pursuing similar goals, particularly how perspectives from inside the policy process can help manage climate change policy.

\section{Background: Carbon Neutral Bhutan}

Bhutan is a small Himalayan nation with less than 800,000 people sandwiched between the world's two most populous nations: India and China. The country is best known to the outside world for its concept of Gross National Happiness (GNH), which is increasingly being acknowledged in the international arena as an alternative development paradigm (Allison,

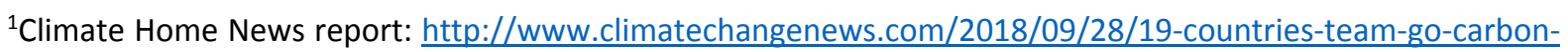
neutral// (accessed on October 22, 2018) 
2012; Brooks, 2013; R. Schroeder \& Schroeder, 2014; Ura, 2015). The essence of GNH is to balance four broad pillars: economic, social, environment and governance. ${ }^{2}$ The four pillars comprise nine domains, 33 indicators and 124 variables (Thinley, 2005; Ura, 2015). The origin and overview of the GNH concept is provided elsewhere (Centre for Bhutan Studies, 2012; Givel, 2015; Munro, 2016) and comprehensive details about GNH and its components and how the GNH index is calculated are provided in Centre for Bhutan Studies $(2012,2016)$. In an effort to embed the GNH principle into policy making and implementation, a GNH policy screening tool was developed and introduced in 2008 by the Centre for Bhutan Studies. The tool is now being used by the GNH Commission of Bhutan (the country's national planning agency), as well as by various national agencies (RGoB, 2015) with an aim to align proposed policies to the GNH strategy.

The country's GNH framework supports the carbon neutral goal; the interplay of these two policy frameworks will be discussed in section 4.1. R. Schroeder and Schroeder (2014) presented GNH as a development model that attempts to decouple economic growth from environmental damage, which is relevant for the contemporary discourse on low emission development (Newman, 2017). Since Bhutan's 2009 pledge was made, a National Low Carbon Strategy was put in place. In addition, maintaining carbon neutrality constitutes one of the sixteen national key result areas under the present Eleventh five-year plan (RGoB, 2013).

Bhutan's net forest cover, which is a cornerstone of the present carbon neutral status, has been maintained at 71\% over decades (Ministry of Agriculture and Forestry, 2017). Currently, the Constitution of Bhutan mandates that the State maintain a minimum forest cover of $60 \%$ into the future (RGoB, 2008). In order to meet and maintain the carbon neutral pledge, Bhutan aims to keep its carbon emissions within the sink capacity of its forest cover, which has, until now, been relatively easily achieved. For example, in 2014, Bhutan was responsible for 2.4 million tonnes of $\mathrm{CO}_{2}$ equivalent emissions (Yangka \& Newman, 2018) - a number far below the sink capacity of 6.3 million tonnes (NEC, 2012).

However, considering that fossil fuel consumption from the transport and industry sectors is rising rapidly as seen in Bhutan's energy balance in 2005 and 2014 (Department of Renewable Energy, 2015; DoE, 2007), the question arises around whether the country's carbon neutral status can be sustained at the same level of ease in the future by relying on its forest cover alone. What impact will a changing climate and weather patterns have on hydropower generation, which remains the key source of energy? What role can, or will, the electricity sector play in the future, particularly in helping to decarbonise? These and other challenges will be examined in this paper.

\section{Methodology}

\subsection{Interview design}

Semi-structured interviews were used as the primary method for data collection in this study. The interview consisted of 20 questions (see Appendix 2), which were conducted on sixteen participants. Ten of the interviews were conducted in person. The remaining six interviews were conducted electronically through emails.

\subsection{Participant selection process}

Key stakeholders were identified based on their official position and duties. The selected participants were either executive or senior level officials working in the core agencies in

\footnotetext{
2 It should be noted that the exact wording/phrase for the four pillars varies in the literature, though not substantively (see Appendix 1 for the lists adopted by various authors). The present study used the four categorical words for simplicity, as they arguably capture the required dimensions.
} 
Bhutan, such as energy, forestry, industry and transport, and the environmental commission, as well as international development partners. These key stakeholders were involved in formulating and implementing national plans, climate change policy and governance of energy in Bhutan. Stakeholders that participated in the study were coded as participant 1, 2, 3, etc., and those who did not consent to identify their organizations were coded as Agency 1, 2, 3, etc. It should be noted that participant responses may not necessarily reflect their organisation's view. Table 1 lists the participants, their organisations and the mode of response.

A potential limitation of this study could be the lack of feedback from local municipality stakeholders, market actors, national civil society groups or the general public, who were not interviewed as part of the research.

\subsection{Design of Questionnaire}

The questions were open-ended to provide rich data and were flexible enough to invite and incorporate additional questions and answers. Given the broad-based implications of carbon neutrality, the list of questions may still fail to address some other pertinent issues. Considering that Bhutan has already pledged for carbon neutrality and reaffirmed it in its NDC under the Paris Agreement (UNFCCC, 2017), this study did not examine why Bhutan should be carbon neutral, but rather focused on how carbon neutrality can be maintained. Some questions varied between stakeholders as only relevant questions were asked to the concerned participants based on their official duties and responsibilities.

\subsection{Data analysis method}

The interview data in this study were analysed with reference to the model proposed by Massey (2011) who categorised data into three levels: articulated, attributional and emergent. Articulated data are the direct responses to the questions raised; attributional data is the information extracted through indirect questions attributed to priori hypothesis or theory; and emergent data are the information that surfaces during the interview without any sort of direct or indirect questions being asked (Massey, 2011). The analysis in the present study is focused mostly on the articulated data and to a lesser degree on the emergent and attributional data. Data were organised and analysed using NVivo Pro (version 11), a computer assisted qualitative data analysis software developed and licensed by QSR International (Leech \& Onwuegbuzie, 2011). The nodes were classified to form the themes, which are presented in section 4 with reference to relevant literature.

\section{Results and Discussion}

Twelve key themes were identified through the analysis, as presented below.

\subsection{Policy Frameworks: Carbon Neutrality, Gross National Happiness and the Sustainable Development Goals}

In general, participants accepted the carbon neutral goal as 'fully-in-sync' with the GNH paradigm, and considered the environmental pillar of $\mathrm{GNH}$ as a crucial enabler to leverage carbon neutrality (participants $4,7,8,13,15$ ). In the same way, carbon neutrality and low carbon development were also seen as essential for upholding the environmental pillar of the GNH paradigm (participants $3,7,13$ ). Thus, there appears to be a positive feedback loop between the carbon neutral goal and the GNH paradigm. Similarly, participant 3 argued that human growth has to co-exist with the environment pointing out that from a GNH perspective, the environment is one of the key components to achieve a happy and sustainable country in the long term. Carbon neutrality was also associated with green growth and sustainable development, not just cutting emissions (participants 6, 13). This is in line with Yangka, 
Newman, Rauland, and Devereux (2018), who propose a 'three G' model - GDP, GNH and GHG's - as a way to develop Bhutan sustainably into the future.

On the relationship between GNH and the UN Sustainable Development Goals (SDGs), participants $(7,13,15)$ agreed that they are similar and complement each other, and remarked that Bhutan is in a strong position to pursue them. Bhutan's readiness to address the SDGs has been attributed to its GNH philosophy (Wangmo, 2016), with Bhutan expected to prioritise three SDGs - Climate Change, Poverty Reduction and Life on Land - as accelerators for others (participant 7). Considering possible complementarity, participant 15 stated that, in the era of the SDGs, 'there could be an opportunity to achieve GNH in a progressive, innovative and positive way'.

\subsection{Institutional issues}

A variety of institutional issues were identified by the participants. These issues were around the existing governance regime, such as the country's laws, regulations and policies, and the organisational set up that steers socio-economic activity, especially those aspects that have a direct impact on the low carbon strategy. Most participants noted that a legislative framework and policies are already in place and there is a strong political will that can sustain carbon neutrality for a long time to come. For instance, the pro-environmental provisions of the Constitution of Bhutan were seen as a platform to enable carbon neutrality (participants 3, 4, $7,13)$.

The vehicle quota system in Bhutan (waived import duty for senior government officials) was highlighted as negating the motto behind the vehicle taxation system - i.e. levying heavy tax on fossil fuelled vehicles and no tax for electric cars (participant 13). The need for interventions in the face of the growing industry and transport sectors was also highlighted (participants 6, 10, 11, 13, 14).

\subsection{Human resource and climate financing issues}

The need for large-scale investment to facilitate a low carbon transition is well understood (Hall, Foxon, \& Bolton, 2015; Mulugetta \& Urban, 2010), and was pointed out by many participants in this study as a key challenge for Bhutan. In particular, the need to fulfil competing socio-economic development needs was highlighted (participants 7,13 ) in light of financing requirements for carbon neutrality. Human resource constraints were identified in the areas of accessing international finance and in using and applying computer aided planning tools (i.e. a lack of staff and/or skills in these two areas), while other respondents either dismissed or did not acknowledge such constraints.

However, participants had different viewpoints on how to garner the financial support required. Participants $(2,6,8,10,15)$ noted that international development partners (eg Japan International Cooperation Agency) are keen to lend support for a carbon neutral Bhutan. Participants $(7,13)$ shared the difficulties of securing climate finance, and further mentioned that significant financial contributions will still be required from the Government of Bhutan. To this end, participant 15 suggested that Bhutan should no longer look at development partners as sources of finances, but rather lean on their technical expertise to gain access to other sources. Nonetheless, a few financing windows were highlighted such as BIOFIN, the Biodiversity Finance initiative of the United Nations Development Programme (UNDP) that aims to address financing issues in biodiversity conservation through global partnership (participant 15), the 'Bhutan for Life Initiative', a transition fund mechanism at the national level for supporting conservation efforts in Bhutan (participants 2, 7), Payment for Environmental Services (PES) schemes for maintaining the watershed area for the sustainability of the hydropower sector (participant 4,12 ) and ecotourism (participant 7). 
Regarding the possibility of an Emissions Trading Scheme (ETS) in Bhutan, participants $(7,15)$ encouraged exploring it, while another $(13)$ rejected it due to the small potential market in Bhutan. However, the Asian Development Bank (ADB, 2016) considers an ETS as an efficient mitigation measure and recommends Asian countries explore this option. Surprisingly, participants $(7,13)$ acknowledged that Bhutan has not carried out any cost estimation to sustain the carbon neutral goal, and studies suggest that Bhutan may face challenges due to human resource and financial constraints (Yangka \& Newman, 2018).

\subsection{Planning tools and the GNH policy screening tool}

Understanding the complex interaction between energy, economy and environment demands the use of analytical tools. However, the interviews revealed a lack of modelling expertise and experience (participants 2, 4, 7, 13, 16), as do previous studies of Bhutan, except for a passing remark from a participant on future work on a Computable Generable Equilibrium model to be used by the World Bank to assess Bhutan's NDC. While having access to a planning tool in itself may not enable carbon neutrality, integrated assessment models are widely applied to quantify future challenges and explore plausible solutions through scenario formulation (Nakata, Silva, \& Rodionov, 2011; Nishioka, 2016; van Vuuren et al., 2016). Participants (2, $4,7)$ reflected on the GNH policy screening tool as being used to align projects and policies towards the GNH strategy by involving a minimum of 15 multi-stakeholders (RGoB, 2015). This could be considered an important area for Bhutan. Considering that only three participants $(2,4,7)$ referred to the GNH policy screening tool when discussing planning tools, it appears to support K. Schroeder (2015) observation that this policy tool is not used by many of the subnational actors. However, given that the screening tool is for policy appraisal, not evaluation, it may not necessarily be used by everyone involved at the operational level. In fact, those at the sub-national level use the simple 'GNH checklist' with a view to aligning development activities to the GNH vision (Centre for Bhutan Studies, 2016).

\subsection{Topography and urbanisation}

The country's topography is seen as an enabler to harness hydropower with minimal socioenvironmental impact, but as a barrier for rail-based transport systems, which is argued to be crucial for decarbonising and decongesting road transport (Newman, 2015; Newman \& Kenworthy, 2015). While Bhutan's small population can be considered as an advantage in maintaining carbon neutrality long-term, some participants $(10,14)$ see this factor as a barrier, due to low population density. Despite a small population, rural-urban migration is leading to rapid urbanisation in Bhutan, which is expected to reach $77 \%$ by 2040 (ADB, 2011). This emerged as a contested issue amongst stakeholders interviewed, though no direct questions were posed on this issue. For example, participant 6 expressed concern over urbanization and rural to urban migration as a threat due to the expected change in people's lifestyles, while others (participants $4,5,16$ ) argued that farmland left fallow in the abandoned villages is already turning into forest cover which ultimately increases the carbon sink capacity. It is also obvious that leaving farmland fallow is a direct threat to food security, which was not expressed by the participants. Notwithstanding this, participant 13 expressed the need for smart and localised city designs as Bhutan urbanises into the future. This highlights how the same issue can be considered either an enabler or a barrier depending on the context. These differing opinions also point towards different sectoral positions and siloed approaches for dealing with policy, highlighting potential challenges to navigating the carbon neutral pathway.

\subsection{Transport and Industry sector}

In Bhutan, the transport and manufacturing industries are emerging as main sources of carbon emissions due to their reliance on fossil fuels (NEC, 2012; Yangka \& Newman, 2018). In 
keeping with this, participants $(2,11,13)$ touched on the importance of cleaner production initiatives in the manufacturing industries. One such successful demonstration was carried out in 2004, which was discontinued due to lack of funds (participant 11). This reflects the challenges to financing (see section 4.3). Concerns over the possible negative impact of planned economic zones (industrial development areas in the southern foothills of Bhutan) and mineral development and extraction (participant 2, 11, 13) on Bhutan's emissions level were raised. While participants acknowledged that much will depend on the policy decision to either go for green industries or to continue with highly polluting industry sectors, the economic development policy remains silent on this pertinent issue (RGoB, 2016).

Participants $(2,4,8,10,14)$ expressed the need to promote electric cars and to advance public bus transportation by improving commuters' accessibility. Participant 8 argued optimistically that it wouldn't be a significant task to phase out fossil fuelled buses and replace these with electric ones considering the small numbers of buses in Bhutan. Conversely, participant 2 cautioned that it is getting late for modal shifting in passenger transport, but that the younger generation may opt for public transport if it is made efficient. With regard to a light rail transport system, some participants $(8,10)$ shared their optimistic viewpoint, while participant 14 expressed concern over its feasibility given Bhutan's small population. This is yet another issue with divergent viewpoints, indicating potential challenges towards sustaining the ambitious climate goal. The possibility of constructing tunnels through the mountains for a shorter transportation distance to reduce fuel consumption and emissions was also expressed (participant 2).

Beyond this, participant 16 envisioned a hydrogen future for fuelling the transport sector in Bhutan. However, at this juncture, no serious undertakings in this direction can be observed in Bhutan. Moreover, visions for hydrogen-based transport systems seem too far away (Whitmarsh \& Wietschel, 2008) and it appears that only end-users perceive it to be a feasible technology, as there are still significant supply side challenges (Kontogianni, Tourkolias, \& Papageorgiou, 2013).

\subsection{Transitioning economy}

Data from the National Statistical Bureau (NSB, 2004, 2017) show that Bhutan is currently transitioning away from a traditional agrarian and forestry based economy towards a more a market based modern economic system, which is likely to result in an increase in carbon emissions. Such socio-economic transitions are a key challenge for Bhutan. For example, the IPAT $($ Impact $=$ Population*Affluence*Technology) identity (Ehrlich \& Holdren, 1971; York, Rosa, \& Dietz, 2003) and the Kaya Identity (IPCC, 2000; Kaya, 1990), which are widely used as analytical frameworks for assessing environmental impacts and their drivers, often correlate increasing per capita GDP and population with rising emissions. In Bhutan, per capita GDP increased from US\$834 in 2003 (NSB, 2004) to US\$2,879 in 2016 (NSB, 2017), and will continue to increase as Bhutan aspires to become a middle-income country by 2023 , leading to an increase in emissions, without significant intervention.

Rising consumerism was seen as a threat to maintaining carbon neutrality (participant 2) and, not surprisingly, was also noted as a threat to the GNH principle (Brooks, 2013; Hayden, 2015). Similarly, touching on the problem with taking a myopic approach to development, participant 15 noted that 'development that creates jobs and ultimately destroys the environment will not achieve happiness; it might make people wealthier in the short term, but it certainly won't make the next generation any wealthier and any happier'. However, participants $(11,13,15)$ noted that Bhutan's current emissions are far lower than their sink capacity, suggesting that there is adequate 'development space' (Yedla \& Garg, 2014) for economic growth as the country aspires to become a middle-income country. 


\subsection{Role of, and issues with, hydropower}

There appears to be much reliance on hydropower, forest cover and a small population for Bhutan to maintain carbon neutrality. Participant 3 proudly acknowledged hydropower as playing a 'singular key role' and having a 'domino effect'. Complementing this, participants $(4,5)$ argued that the advent of hydropower development had led to forest regeneration through less use of firewood. Participants $(13,15)$, however, argued that while hydropower helps in reducing emissions from electricity generation, it does not increase the carbon sink capacity, and further cautioned about the risk of relying on a relative mono-economy - that is, an economy affected by a single economic sector - hydropower, in the case of Bhutan.

Notwithstanding the divergent viewpoints, the literature shows that hydropower as a renewable energy source also has its own share of criticism. For instance, some research argues that the decomposition of submerged vegetation from hydropower dams contributes to methane and $\mathrm{CO}_{2}$ emissions (S. Li, Wang, Zhou, Cheng, \& Wang, 2018; Zarfl, Lumsdon, Berlekamp, Tydecks, \& Tockner, 2015). Based on emissions data from 85 hydroelectric dams with global distribution, Barros et al. (2011) identify that emissions are lower in high latitude and temperate regions compared to those in tropical regions. Thus, given that Bhutan is a temperate country located far from the equator and high up in the Himalayas, emissions are likely to be lower than other regions. Bhutanese hydropower developers also carry out compensatory tree plantation in lieu of forest removal during construction. Hydropower in Bhutan also primarily consists of run-of-the-river schemes with no large reservoirs to store water. Nevertheless, it is likely that emissions would still occur from the decomposition of vegetation in the dams, as well as embodied emissions from construction materials (participant 2).

Based on concerns over intermittency, high cost and low plant load factor ${ }^{3}$, participants $(3,4,5)$ dismissed and discouraged electricity generation from non-hydro renewable energy sources. Others, however, argued that the absence of a feed-in-tariff policy was a barrier to promoting non-hydro renewable energy (participants 1, 2,9). On the socio-environmental impact of hydropower, participants $(4,5,16)$ argued that hydropower dams in Bhutan are located in deep gorges where there are no or fewer human settlements, and that they are nowhere near the size of dams in neighbouring countries. It was also pointed out that service delivery in terms of efficiency and reliability of the electricity transmission and distribution systems could be improved further to encourage end-users to switch towards clean electricity (participants 1, 4, 9). Issues around the impact of climate change on hydropower are discussed further in section 4.11 .

\subsection{Conflict with ecotourism}

Hydropower has also been identified in the literature as being in potential conflict with ecotourism, which is considered as an emerging source of finance for Bhutan (participant 7). For instance, Fletcher (2010) highlights the ongoing debate between dam builders and ecotourism operators, notably white-water kayaking operators in Costa Rica - a country that has also pledged to be carbon neutral by 2021 and which also largely relies on its hydropower for clean electricity. He argues that this debate is a conflict between two different efforts to capitalise on water resources, rather than between capitalism and conservation, but cautions that promoting hydropower as an effective climate change mitigation policy is exacerbating this conflict. While the interview results did not identify these conflicts, there is potential for them to arise in the future, given that both the tourism and hydropower sectors contribute significantly to Bhutan's GDP. At the same time, both these sectors also operate within the policy framework of minimal environmental damage, that is, 'high value, low impact' for tourism and run-of-the-river schemes for hydropower.

\footnotetext{
${ }^{3}$ The percentile value of the actual generation to the rated generation capacity of a power plant.
} 
The role of Bhutan's GNH screening tool, which to date had been dealing with new policy issues one at a time, could be used to examine a macro-comparison between these two crucial activities and policies. With regard to emissions from international travel (including tourism), these are usually excluded from national GHG inventories (IPCC, 2006), though Flagg (2018) raised concerns about this issue for Costa Rica. In Bhutan, emissions from jet fuels used in aviation are included under the transport sector (NEC, 2011), though not disaggregated into tourist and non-tourist shares due to data paucity. Interestingly, these issues identified in the literature did not emerge during the interviews.

\subsection{Forest cover and carbon accounting issues}

Bhutan's Constitution mandates the state to maintain a minimum forest cover of $60 \%$ and at present it stands at 71\% (Ministry of Agriculture and Forestry, 2017). The concept of 'forest as the baseline' (participants 13,15), confirms the importance of Bhutan's forests to sustain carbon neutrality. Participant 12 suggested to bring degraded and barren land under tree plantations to increase forest cover, but cautioned on the cost to forest conservation, which is being experienced by villages in the form of human-wildlife conflict. ${ }^{4}$ The same participant highlighted the existence of compensatory mechanisms, where trees will need to be planted to compensate for forest land converted to other land uses (i.e. infrastructure development). Participant 6 cautioned against the possible reduction in sequestration capacity due to ageing forests. To address this issue, participant 12 suggested increasing sustainable forest management practices, stating that:

'Bhutan could remain carbon neutral provided we are able to manage our forest on the principles of sustainability and other sectors take actions on mitigation [reduction] of greenhouse gases'.

Notwithstanding its crucial role, forest carbon sequestration is also a highly contested issue similar to that for hydropower. For example, the actual amount of carbon sequestration depends on the forest growth rate, soil carbon cycle and temperature of the forest site (van Kooten, 2017), and is impacted by worldviews on the relationship between environment and development (Bääckstrand \& Löövbrand, 2006).

In the agriculture sector, farm mechanisation was seen as supporting carbon neutrality through land intensification, thereby avoiding conversion of forest land to agricultural land (participant 12).

\subsection{Climate change impacts}

The impact of climate change is widely recognized as threatening the core economic activities of Bhutan such as forestry, agriculture, tourism and hydropower (Hoy, Katel, Thapa, Dendup, \& Matschullat, 2015; NEC, 2011). An apparent paradox is that Bhutan relies on forest cover and hydropower potential for its carbon neutrality status, but these are at risk of climate induced damages. There are studies that highlight glacier retreat and a decrease in precipitation levels in the Himalayas (H. Li, Xu, Beldring, Tallaksen, \& Jain, 2016). Surprisingly, participants (4, $5)$ do not envisage any near- to medium-term climate induced problems for hydropower. In fact, participants $(3,4)$ believed that there would be no definitive outcome of climate change impact in the Himalayas, in particular on hydropower. Participants $(1,3,5,9,16)$ believed that reservoir hydropower could be built to mitigate the impacts of changing hydrology in the event of acute climate change impacts. These issues highlight a need for support to undertake more international research on these issues including how they could impact on Bhutan. Climate change is also expected to cause disruption to ecosystems, and thus potentially increasing human-wildlife conflict in Bhutan (Hoy, et al., 2015).

\footnotetext{
${ }^{4}$ Wildlife encroaching onto farmland and destroying crops undermining rural livelihood
} 


\subsection{Other concerns}

During the interview process, emergent data arose from some of the participants. For instance, participants $(4,13)$ raised concern over economic growth and equitable development, pointing out that only a handful of shareholders benefit from dirty and heavily polluting industrial development, and argued that economic development need not necessarily be industrial growth. Creating a sufficient number of jobs quickly in sustainable enterprises and the need for economic diversification, were noted as a key challenge that Bhutan may face in the near future (participant 15). Furthermore, concerns were raised around Bhutan not deriving sufficient national benefits from its efforts to contribute to the global environment (participant 2). In this vein, participant 4 pointed out that:

'Sometimes we go off, slightly more ambitious in our commitments to the external world, we offer more and that is the scary part. Let's be happy that we are carbon neutral and have $60 \%$ forest cover. We may overdo it. Set [an] example? - I think the world is too large for us. Let's get better off! The fear is trying to say we will do more, I think will be a disservice to the Bhutanese people'.

\section{Sustaining carbon neutrality}

Sections 4.1 to 4.12 highlighted the issues that shed light on the challenges and plausible solutions to sustain Bhutan's carbon neutrality. These are summarised in the following sections.

\subsection{Challenges to sustaining carbon neutrality}

The concept of carbon neutrality has been characterised as an idealised emission reduction strategy (Birchall, 2014), suggesting significant challenges to its implementation and ultimate achievement. Fankhauser (2013) identifies the challenges for low carbon growth as the need to have a strong legal basis and a credible roadmap with implementation plans, along with the need to manage wider socio-economic consequences. Low carbon transition is recognised as highly contested and disruptive (Geels, Sovacool, Schwanen, \& Sorrell, 2017a) and filled with socio-environmental conflicts (Weber \& Cabras, 2017). The interview responses discussed in sections 4.1 to 4.12 touched on many of these challenges, and they are grouped into two broad dimensions: areas where respondents agreed and other areas where their viewpoints diverged (see Table 2). Despite some disagreement among the stakeholders, there was no evidence of potential conflicting views between a participant and his/her agency, although some of them cautioned on this issue prior to the interview process.

Where participants' viewpoints aligned or diverged, Table 2 highlights some of the potential challenges and solutions that could enable or hinder implementation of carbon neutral policy. Any areas of concern raised only by a single participant (for example, issues around ageing trees on carbon sequestration) are not listed in the table. While numerous issues were identified through the interview process on the future challenges of sustaining carbon neutrality, it is also evident that several potential issues identified in the literature were neither raised nor discussed among many of the stakeholders. This neglect could emerge as a potential risk, as highlighted by Fankhauser (2013) around the need for policy competence. It seems that the key challenge would be to strengthen those areas of agreement and address those areas of disagreement. Examples of areas of agreement include that financial support is required and that transport and manufacturing industries are major emitters, while areas still in contention include the need for an emissions trading scheme and whether intervention is even required. 


\subsection{Solutions to assist with upholding carbon neutrality into the future}

As outlined in Table 2, there were several areas where respondents agreed. Much optimism seems to arise from the forest cover and hydropower potential, which underpin Bhutan's carbon neutral pledge. These two factors are perhaps the key internal determinants, which could be labelled as the 'resource advantages' for Bhutan in the context of carbon neutral development - offsetting and avoiding emissions - that support its ambitious climate policy innovation and implementation.

Not surprisingly, the GNH strategy and the pro-environmental provisions of the Constitution of Bhutan support the goal of carbon neutral development. In fact, it appears that the GNH strategy has been effective in instilling environmentally benign policies in Bhutan, in that the environmental pillar of GNH consists of several variables to account for ecological diversity and resilience. In brief, it can be argued that the two strategies taken together form a powerful legislative framework creating a conducive environment to navigate the carbon neutral pathway. These are unique internal determinants which, when complemented by the two resource advantages, make up a formidable combination for Bhutan to pursue and sustain carbon neutrality into the future. The case of Costa Rica is a close comparison (see Flagg (2018) for details).

Despite being hopeful, there is a need for policy intervention to ensure Bhutan's development remains on a low carbon trajectory. Options such as phasing out traditional bioenergy in the building sector, accelerating electric transport and exploring industrial symbiosis were demonstrated through a long term energy-economy modelling study (Yangka $\&$ Newman, 2018). Similar initiatives have also been highlighted in the literature (Government of India, 2014; Newman, 2015; Shakya \& Shrestha, 2011; Shrestha, Ahmed, Suphachalasai, \& Lasco, 2013). Beyond the technological solutions, the need to raise awareness about the impacts of GHG emissions among the general public was also suggested. Although afforestation, including bringing more forest cover under sustainable forest management, provides a promising approach for ensuring carbon neutrality, Bhutan should also take stock of the potential unintended consequences of forest conservation and aggressive hydropower development.

In light of the termination of carbon neutral programmes in New Zealand due to changes to leadership (Birchall, 2014), continuity of 'strong political will' seems essential. Research has also found that political stability, rule of law and control of corruption can have a mitigating effect on carbon emissions (Gani, 2012).

Considering that financial constraints emerged as one of the key challenges for Bhutan, exploring the long-term sustainability of the 'Bhutan for Life Initiative', and vigorous analysis of BIOFIN to garner available funding could help to address this. PES activities could be expanded to provide financial support to communities living in and around the catchment area of the riverine system for good health of the hydropower sector.

It is clear that the electricity sector is going to play a much greater role in the future in terms of providing energy to households and for electric transport. If the primary source of electricity continues to be hydropower, this will ensure emissions are kept low and help to maintain carbon neutrality, particularly as demand for these services increase.

\section{Conclusion}

This study has ventured inside the policy making and implementation process in Bhutan that has been given the task of balancing and integrating the multiple objectives of GDP, GNH and GHG mitigation. The interviews highlight that respondents are acutely aware that Bhutan is providing an example of what other countries will need to strive for in the coming years. However, they are also intent on maintaining growth in GDP and GNH which may impact on 
their ability to continue with the carbon neutral status. Various challenges were discussed around upholding carbon neutrality in Bhutan in the long term, without more ambitious low carbon interventions. The desire to leave climate policy as it is, without any change, is the easiest way forward in the short term for those dealing with complex trade-offs in development policy. However, in the long term, all participants noted the need to find solutions that could simultaneously improve the economy and happiness of Bhutan, as well as maintain its carbon neutrality.

The core policy options continue to be maintaining forest cover and increasing the amount of clean hydroelectricity, backed up by continuing strong political will and legislative framework. The extra interventions required in industry and transport to decarbonise development are likely to be a test for policy makers as they are not yet able to see how this can be done without impacting on the other goals. If policy makers remain complacent about the potential challenges and opportunities that are likely to be associated with these interventions, this could undermine Bhutan's ability to uphold its ambitious climate policy.

The interviews also revealed some divergent viewpoints among the participants that have the potential to hinder the formulation of appropriate policy measures to meet future challenges. The divergent viewpoints call for effective consultation and collaboration among various stakeholders within different sectoral positions.

Contemporary socio-economic issues such as the need to create employment and equitable income growth also emerged. Some even cautioned that Bhutan's over-commitment to the environment could potentially be a disservice to the Bhutanese people. All this suggests challenges to integrating the three aforementioned core goals.

The findings of this paper could form the basis for future research that could also explore the views of civil society, the general public and private sector stakeholders (not included in this study). This would likely reveal other challenges in Bhutan's carbon neutral journey, particularly around adoption of new behaviours and technologies.

While this study was specific to Bhutan, the likely challenges and plausible solutions identified, as well as the broader socio-economic issues that emerged during the interviews, are likely to be relevant to other countries aspiring to implement ambitious climate policies, while also growing their economies. Examining how Bhutan maintains its carbon neutral path on the ground will provide many lessons to other countries, not only for developing countries who may want to adopt such ambitious goals, but also to the industrialized world.

\section{Conflict of Interest}

The authors declare no conflict of interest. The funding sponsors had no role in the design of the study; in the collection, analyses, or interpretation of data; in the writing of the manuscript, and in the decision to publish the results. 


\section{References}

ADB. (2011). Bhutan Transport 2040 Integrated Strategic Vision: Asian Development Bank. ADB. (2016). Asian development outlook 2016 update. Meeting the low-carbon growth challenge. (A. D. Bank, Trans.). Manila: Asian Development Bank.

Allison, E. (2012). Gross National Happiness. The Berkshire Encyclopedia of Sustainability: measurements, indicators, and research methods for sustainability, 180-184.

Bääckstrand, K., \& Löövbrand, E. (2006). Planting Trees to Mitigate Climate Change: Contested Discourses of Ecological Modernization, Green Governmentality and Civic Environmentalism. Global Environmental Politics, 6(1), 50-75. doi: 10.1162/glep.2006.6.1.50

Barros, N., Cole, J. J., Tranvik, L. J., Prairie, Y. T., Bastviken, D., Huszar, V. L. M., et al. (2011). Carbon emission from hydroelectric reservoirs linked to reservoir age and latitude. Nature Geoscience, 4, 593. doi: 10.1038/ngeo1211

Birchall, J. (2014). New Zealand's abandonment of the Carbon Neutral Public Service programme. Climate Policy, 14(4), 525-535. doi: 10.1080/14693062.2014.877224

Brooks, J. S. (2013). Avoiding the Limits to Growth: Gross National Happiness in Bhutan as a Model for Sustainable Development. Sustainability, 5(9), 3640-3664. doi: $10.3390 /$ su5093640

Bushell, S., Buisson, G. S., Workman, M., \& Colley, T. (2017). Strategic narratives in climate change: Towards a unifying narrative to address the action gap on climate change. Energy Research \& Social Science, 28, 39-49. doi: https://doi.org/10.1016/j.erss.2017.04.001

Carbon Neutrality Coalition. (2017). Declaration of the Carbon Neutrality Coalition: High Level Event at COP23. Bonn, Germany.

Centre for Bhutan Studies. (2012). An extensive analysis of GNH Index K. Ura, S. Alkire, T. Zangmo \& K. Wangdi (Eds.), Retrieved from http://www.grossnationalhappiness.com/wpcontent/uploads/2012/10/An\%20Extensive\%20Analysis\%20of\%20GNH\%20Index.pdf

Centre for Bhutan Studies. (2016). A Compass Towards a Just and Harmonious Society: 2015 GNH Survey Report Retrieved from http://www.grossnationalhappiness.com/wpcontent/uploads/2017/01/Final-GNH-Report-jp-21.3.17-ilovepdf-compressed.pdf

Department of Renewable Energy. (2015). Bhutan Energy Data Directory. Thimphu, Bhutan: Department of Renewable Energy.

DoE. (2007). Bhutan Energy Data Directory 2005. Thimphu, Bhutan: Department of Energy.

Ehrlich, P. R., \& Holdren, J. P. (1971). Impact of Population Growth. Science, New Series, 171(3977), 1212-1217.

Fankhauser, S. (2013). A practitioner's guide to a low-carbon economy: lessons from the UK. Climate Policy, 13(3), 345-362. doi: 10.1080/14693062.2013.749124

Flagg, J. (2015). Aiming for zero: what makes nations adopt carbon neutral pledges? Environmental Sociology, 202-212. doi: http://dx.doi.org/10.1080/23251042.2015.1041213

Flagg, J. (2018). Carbon Neutral by 2021: The Past and Present of Costa Rica's Unusual Political Tradition. Sustainability, 10(2), 296.

Fletcher, R. (2010). When Environmental Issues Collide: Climate Change and the Shifting Political Ecology of Hydroelectric Power. Peace \& Conflict Review, 5(1), 14-30.

Gani, A. (2012). The relationship between good governance and carbon dioxide emissions: Evidence from developing economies. Journal of Economic Development, 37(1), 77-93.

Geels, F. W., Sovacool, B. K., Schwanen, T., \& Sorrell, S. (2017a). The Socio-Technical Dynamics of Low-Carbon Transitions. Joule, 1(3), 463-479. doi: https://doi.org/10.1016/i.joule.2017.09.018

Geels, F. W., Sovacool, B. K., Schwanen, T., \& Sorrell, S. (2017b). Sociotechnical transitions for deep decarbonization. Science, 357(6357), 1242-1244. doi: 10.1126/science.aao3760 
Givel, M. S. (2015). Gross National Happiness in Bhutan: Political Institutions and Implementation. Asian Affairs, 46(1), 102-117. doi: 10.1080/03068374.2014.993179

Government of India. (2014). The Final Report of the Expert Group on Low Carbon Strategies for Inclusive Growth. New Delhi, India: Planning Commission of India.

Hall, S., Foxon, T. J., \& Bolton, R. (2015). Investing in low-carbon transitions: energy finance as an adaptive market. Climate Policy, 17(3), 280-298. doi: 10.1080/14693062.2015.1094731

Haszeldine, R. S., Flude, S., Johnson, G., \& Scott, V. (2018). Negative emissions technologies and carbon capture and storage to achieve the Paris Agreement commitments. Philosophical Transactions of the Royal Society, A 376: 20160447(2119). doi: 10.1098/rsta.2016.0447

Hayden, A. (2015). Bhutan: Blazing a Trail to a Postgrowth Future? Or Stepping on the Treadmill of Production? The Journal of Environment \&amp; Development, 24(2), 161-186. doi: $10.1177 / 1070496515579199$

Höhne, N., Kuramochi, T., Warnecke, C., Röser, F., Fekete, H., Hagemann, M., et al. (2017). The Paris Agreement: resolving the inconsistency between global goals and national contributions. Climate Policy, 17(1), 16-32. doi: 10.1080/14693062.2016.1218320

Hoy, A., Katel, O., Thapa, P., Dendup, N., \& Matschullat, J. (2015). Climatic changes and their impact on socio-economic sectors in the Bhutan Himalayas: an implementation strategy. Regional Environmental Change, 16(5), 1401-1415. doi: 10.1007/s10113-015-0868-0

IPCC. (2000). Scenario driving forces. In N. Nakićenović (Ed.), Special Report on Emissions Scenarios: A special report of working group III of the Intergovernmental Panel on Climate Change. Cambridge: Cambridge Cambridge University Press.

IPCC. (2006). Reporting Guidance and Tables. In M. J. S. Sánchez, S. Bhattacharya \& K. Mareckova (Eds.), 2006 IPCC Guidelines for National Greenhouse Gas Inventories IPCC, Geneva, Switzerland: Intergovernmental Panel on Climate Change,.

IPCC. (2014). Climate Change 2014: Synthesis Report. Contribution of Working Groups I, II and III to the Fifth Assessment Report of the Intergovernmental Panel on Climate Change [Core Writing Team, R.K. Pachauri and L.A. Meyer (eds.)]. In R. K. Pachauri \& L. A. Meyer (Eds.). IPCC, Geneva, Switzerland: Intergovernmental Panel on Climate Change,.

IPCC. (2018). Summary for Policy makers. In V. Masson-Delmotte, P. Zhai, H. O. Pörtner, D. Roberts, J. Skea, P. R. Shukla, A. Pirani, W. Moufouma-Okia, C. Péan, R. Pidcock, S. Connors, J. B. R. Matthews, Y. Chen, X. Zhou, M. I. Gomis, E. Lonnoy, T. Maycock, M. Tignor \& T. Waterfield (Eds.), Global warming of $1.5^{\circ} \mathrm{C}$. An IPCC Special Report on the impacts of global warming of $1.5^{\circ} \mathrm{C}$ above pre-industrial levels and related global greenhouse gas emission pathways, in the context of strengthening the global response to the threat of climate change, sustainable development, and efforts to eradicate poverty: Intergovernmental Panel on Climate Change.

Kaya, Y. (1990). Impact of Carbon Dioxide Emission Control on GNP Growth: Interpretation of Proposed Scenarios. Paper presented to the IPCC Energy and Industry Subgroup, Response Strategies Working Group, Paris.

Kontogianni, A., Tourkolias, C., \& Papageorgiou, E. I. (2013). Revealing market adaptation to a low carbon transport economy: Tales of hydrogen futures as perceived by fuzzy cognitive mapping. International Journal of Hydrogen Energy, 38(2), 709-722. doi: https://doi.org/10.1016/j.ijhydene.2012.10.101

Leech, N. L., \& Onwuegbuzie, A. J. (2011). Beyond constant comparison qualitative data analysis: Using NVivo. School Psychology Quarterly, 26(1), 70-84. doi: 10.1037/a0022711

Li, H., Xu, C.-Y., Beldring, S., Tallaksen, L., \& Jain, S. (2016). Water Resources Under Climate Change in Himalayan Basins. Water Resources Management, 30(2), 843-859. doi: 10.1007/s11269-015-1194-5 
Li, S., Wang, F., Zhou, T., Cheng, T., \& Wang, B. (2018). Carbon dioxide emissions from cascade hydropower reservoirs along the Wujiang River, China. Inland Waters, 8(2), 157166. doi: 10.1080/20442041.2018.1442040

Massey, O. T. (2011). A proposed model for the analysis and interpretation of focus groups in evaluation research. Eval Program Plann, 34(1), 21-28. doi: 10.1016/j.evalprogplan.2010.06.003

Ministry of Agriculture and Forestry. (2017). National Forest Inventory Report: Stocktaking Nation's forest resources. Thimphu, Bhutan: Ministry of Agriculture and Forestry Retrieved from http://www.dofps.gov.bt/wp-content/uploads/2017/07/National-Forest-InventoryReport-Vol1.pdf.

Mulugetta, Y., \& Urban, F. (2010). Deliberating on low carbon development. Energy Policy.

Munro, L. T. (2016). Where Did Bhutan's Gross National Happiness Come From? The Origins of an Invented Tradition. Asian Affairs, 47(1), 71-92. doi: 10.1080/03068374.2015.1128681

Nakata, T., Silva, D., \& Rodionov, M. (2011). Application of energy system models for designing a low-carbon society. Progress in Energy and Combustion Science, 37(4), 462502. doi: 10.1016/j.pecs.2010.08.001

NEC. (2011). Second National Communication to the UNFCCC. Thimphu, Bhutan: National Environment Commission Retrieved from http://www.nec.gov.bt/nec1/wpcontent/uploads/2012/11/Bhutan-SNC-final-sm.pdf.

NEC. (2012). National Strategy and action plan for low carbon development. Thimphu, Bhutan: National Environment Commission Retrieved from http://www.nec.gov.bt/nec1/wp-content/uploads/2012/11/CNS-final-low-carbon.pdf.

Newman, P. (2015). Transport infrastructure and sustainability: a new planning and assessment framework. Smart and Sustainable Built Environment, 4(2), 140-153. doi: 10.1108/sasbe05-2015-0009

Newman, P. (2017). Decoupling Economic Growth from Fossil Fuels. Modern Economy, 08(06), 791-805. doi: 10.4236/me.2017.86055

Newman, P., \& Kenworthy, J. (2015). The End of Automobile Dependence - How Citites are Moving Beyond Car-based Planning. Washington DC: Island Press.

Nishioka, S. e. (2016). Enabling Asia to Stabilise the Climate / edited by Shuzo Nishioka (1st ed. 2016.. ed.): Singapore : Springer Singapore : Imprint: Springer.

NSB. (2004). Bhutan national accounts statistics. THimphu: National Statistical Bureau.

NSB. (2017). National accounts statistics. Thimphu: National Statistical Bureau.

Oladokun, V. O., \& Asemota, O. C. (2015). Unit cost of electricity in Nigeria: A cost model for captive diesel powered generating system. Renewable and Sustainable Energy Reviews, 52, 35-40. doi: 10.1016/j.rser.2015.07.028

Rauland, V., \& Newman, P. (2015). Decarbonising Cities : Mainstreaming Low Carbon Urban Development / by Vanessa Rauland, Peter Newman: Cham : Springer International Publishing : Imprint: Springer.

RGoB. (2008). The Constitution of the Kingdom of Bhutan. Thimphu: Retrieved from http://www.nationalcouncil.bt/assets/uploads/files/Constitution $\% 20 \% 20$ of $\% 20$ Bhutan $\% 20$ English.pdf.

RGoB. (2013). Eleventh Five Year Plan - Volume I: Main Document. Thimphu, Bhutan: Royal Government of Bhutan.

RGoB. (2015). Protocol for Policy Formulation. Thimphu, Bhutan: Retrieved from https://www.gnhc.gov.bt/en/wp-content/uploads/2017/05/policy0001.pdf.

RGoB. (2016). Economic Development Policy. Thimphu: Royal Government of Bhutan Retrieved from http://www.gnhc.gov.bt/en/wp-content/uploads/2017/05/EDP-2016.pdf. 
Rogelj, J., Schaeffer, M., Meinshausen, M., Knutti, R., Alcamo, J., Riahi, K., et al. (2015). Zero emission targets as long-term global goals for climate protection. Environmental Research Letters, 10(10), 105007. doi: 10.1088/1748-9326/10/10/105007

Schroeder, K. (2015). Cultural Values and Sustainable Tourism Governance in Bhutan. Sustainability, 7(12), 16616-16630. doi: 10.3390/su71215837

Schroeder, R., \& Schroeder, K. (2014). Happy Environments: Bhutan, Interdependence and the West. Sustainability, 6, 3521-3533.

Shakya, S. R., \& Shrestha, R. M. (2011). Transport sector electrification in a hydropower resource rich developing country: Energy security, environmental and climate change cobenefits. Energy for Sustainable Development, 15(2), 147-159. doi: 10.1016/j.esd.2011.04.003

Shrestha, R. M., Ahmed, M., Suphachalasai, S., \& Lasco, R. (2013). Economics of reducing Greenhouse gas emissions in South Asia: options and cost.pdf. Mandaluyong: Asian Development Bank.

Skea, J. I. M., \& Nishioka, S. (2008). Policies and practices for a low-carbon society. Climate Policy, 8(sup1), S5-S16. doi: 10.3763/cpol.2008.0487

Thinley, J. Y. (2005). What Does Gross National Happiness (GNH) Mean? Paper presented at the Rethinking Development: 2nd International Conference on GNH, Halifax, Canada.

UNFCCC. (2009). Report of the Conference of the Parties on its Fifteenth Session, Held in Copenhagen Copenhagen: United Nations Framework Convention on Climate Change.

UNFCCC. (2017). Bhutan First Nationally Determined Contribution. UN Campus, Germany: NDC Registry, United Nations Framework Convention on Climate Change.

Ura, K. (2015). The Experience of Gross National Happiness as Development Framework Retrieved from https://www.adb.org/sites/default/files/publication/177790/gnhdevelopment-framework.pdf

van Kooten, G. C. (2017). Forest carbon offsets and carbon emissions trading: Problems of contracting. Forest Policy and Economics, 75, 83-88. doi: 10.1016/j.forpol.2016.12.006

van Vuuren, D. P., van Soest, H., Riahi, K., Clarke, L., Krey, V., Kriegler, E., et al. (2016). Carbon budgets and energy transition pathways. Environmental Research Letters, 11(7), 075002. doi: 10.1088/1748-9326/11/7/075002

Wangmo, T. (2016) Starting Strong on the SDGs in Asia: Readiness in Bhutan. IGES Discussion paper. Kanagawa, Japan: Institute for Global Environmental Strategies.

Weber, G., \& Cabras, I. (2017). The transition of Germany's energy production, green economy, low-carbon economy, socio-environmental conflicts, and equitable society. Journal of Cleaner Production, 167, 1222-1231. doi: https://doi.org/10.1016/j.jclepro.2017.07.223

Whitmarsh, L., \& Wietschel, M. (2008). Sustainable Transport Visions: What Role for Hydrogen and Fuel Cell Vehicle Technologies? Energy \& Environment, 19(2), 207-226. doi: 10.1260/095830508783900816

Yangka, D., \& Newman, P. (2018). Bhutan: Can the $1.5^{\circ} \mathrm{C}$ Agenda Be Integrated with Growth in Wealth and Happiness? Urban Planning, 3(2), 94-112. doi: 10.17645/up.v3i2.1250

Yangka, D., Newman, P., Rauland, V., \& Devereux, P. (2018). Sustainability in an Emerging Nation: The Bhutan Case Study. Sustainability, 10(5), 1622.

Yedla, S., \& Garg, S. (2014). Two Decades of International Climate Negotiations - Carbon Budget Allocation Approach to Re-shaping Developing Country Strategies. Journal of East Asian Economic Integration, 18(3), 277-299. doi: 10.11644/kiep.jeai.2014.18.3.283

York, R., Rosa, E. A., \& Dietz, T. (2003). STIRPAT, IPAT and ImPACT: analytic tools for unpacking the driving forces of environmental impacts. Ecological Economics, 46(3), 351365. doi: 10.1016/s0921-8009(03)00188-5 
Zarfl, C., Lumsdon, A. E., Berlekamp, J., Tydecks, L., \& Tockner, K. (2015). A global boom in hydropower dam construction. [journal article]. Aquatic Sciences, 77(1), 161-170. doi: 10.1007/s00027-014-0377-0 
TABLE 1 List of Participants

\begin{tabular}{|l|l|l|l|}
\hline Sl\# & Name of Participant & Organisation & Mode of response \\
\hline 1 & Participant 1 & Agency 1 & Written response \\
\hline 2 & Participant 2 & Agency 2 & Written response \\
\hline 3 & Participant 3 & Agency 3 & Voice recording \\
\hline 4 & Participant 4 & Agency 4 & Voice recording \\
\hline 5 & Participant 5 & Agency 5 & Voice recording \\
\hline 6 & Participant 6 & Agency (JICA) & Voice recording \\
\hline 7 & Participant 7 & $\begin{array}{l}\text { Gross National Happiness Commission } \\
\text { (GNHC) }\end{array}$ & Voice recording \\
\hline 8 & Participant 8 & Bhutan Postal Corporation Limited & Written response \\
\hline 9 & Participant 9 & Bhutan Power Corporation Limited & Written response \\
\hline 10 & Participant 10 & $\begin{array}{l}\text { Road Safety and Transport Authority } \\
\text { (RSTA) }\end{array}$ & Written response \\
\hline 11 & Participant 11 & $\begin{array}{l}\text { Department of Industry, Ministry of } \\
\text { Economic Affairs }\end{array}$ & Voice recording \\
\hline 12 & Participant 12 & $\begin{array}{l}\text { Department of Forestry and Park } \\
\text { Services }\end{array}$ & Written response \\
\hline 13 & Participant 13 & $\begin{array}{l}\text { National Environment Commission } \\
\text { (NEC) }\end{array}$ & Voice recording \\
\hline 14 & Participant 14 & City Bus Service & Voice recording \\
\hline 15 & Participant 15 & $\begin{array}{l}\text { United Nations } \\
\text { Programme (UNDP) } \\
\text { Department of Renewable Energy }\end{array}$ & Voice recording \\
\hline 16 & Participant 16 & \multicolumn{2}{|c|}{ Voice recording } \\
\hline
\end{tabular}

TABLE 2 Areas of agreement and disagreement among Participants

\begin{tabular}{|l|l|}
\hline Areas of agreement & Areas of disagreement \\
\hline $\begin{array}{l}\text { The presence of ambitious legislative } \\
\text { framework }\end{array}$ & The impact of the country's topography \\
\hline $\begin{array}{l}\text { GNH strategy is an enabler for carbon } \\
\text { neutrality }\end{array}$ & $\begin{array}{l}\text { Whether intervention is required } \\
\text { considering existing policies }\end{array}$ \\
\hline Hydropower and forest resources as enablers & The role of international financial support \\
\hline The benefits of a small population & Rural-urban migration and urbanization \\
\hline The need to have financial support & The need for rail-based transport system \\
\hline $\begin{array}{l}\text { Transport and manufacturing industries as } \\
\text { major emitters }\end{array}$ & The need for an emission trading scheme \\
\hline
\end{tabular}

